\title{
MPPT using Pitch Angle with Various Control Algorithms in Wind Energy Conversion System
}

\author{
I. ARUL ${ }^{1}$, \\ Research Scholar, \\ Centre for Information \\ Technology and \\ Engineering, M.S \\ University, \\ Tirunelveli, India.
}

\author{
M.KARTHIKEYAN ${ }^{2}$, \\ Prof \& Head, \\ Department of ECE, \\ Tamilnadu College of \\ Engineering, \\ Coimbatore, India.
}

\author{
N.KRISHNAN ${ }^{3}$ \\ Prof. \& Head, \\ Centre for Information \\ Technology and \\ Engineering, M.S \\ University, Tirunelveli,
} India.

\author{
P.ANUSH ${ }^{4}$ \\ Research Scholar, \\ College of Engineering, \\ Guindy, \\ Chennai, India
}

\begin{abstract}
This paper discusses the performance of various intelligent control schemes in extracting maximum wind power using doubly fed induction generator (DFIG). Intelligent control scheme such as fuzzy, neuro-fuzzy, and genetic algorithm based fuzzy controllers are applied for pitch control of DFIG based wind generation system. Wind generation system with eight numbers of identical $1.5 \mathrm{MW}$ wind generators with reactive and real load is considered. Performance of various intelligent controllers is compared with PID controllers. Simulation results show that the performance of intelligent controllers better than PID controllers and in particular GA based fuzzy controller is better than other intelligent controllers.
\end{abstract}

\section{Keywords:}

PI Controller, DFIG, Pitch Control, Fuzzy systems, Genetic Algorithm, Neuro-fuzzy.

\section{INTRODUCTION}

Wind Energy has been the fastest growing renewable energy sector in the country. Normally the wind turbine operates at fixed speed or variable speed, in which the power generation system is maintained. In our paper, we have studied the various importances of controllers which are to used to maximize the power generation. Doubly fed Induction Generator (DFIG) which is used in variable speed wind turbines for producing a constant voltage and frequency in wind energy system. Also it provides a wide support in overall control in power factor. Optimization of wind energy system can be resolved either by using Pitch angle control for genetic algorithm. Rule based fuzzy logic controllers are useful when the system dynamics are not well known.

In order to achieve the maximum power point tracking (MPPT) control, some control schemes have been researched. The design of the system using various intelligent controllers such as variable-speed, variablepitch wind turbines with fuzzy, neuro-fuzzy and genetic tuned fuzzy controllers are considered in this paper.
The proposed Genetic algorithm controller approach gives a maximum power in variable speed wind turbine. In which the speed controller can continuously adjust the speed of the rotor to maintain the tip speed ratio constant at the level which gives the maximum power coefficient, and then the efficiency of the turbine will be significantly increased. The comparison of different strategies with various controllers has been analyzed and the model is simulated under MATLAB.

\section{WIND TURBINES AND CONVERSION SYSTEMS}

The wind energy conversion system has four major components built with a wind turbine, generator, interconnection apparatus and control systems. Generally wind turbines can be classified into two type's namely vertical axis type and the horizontal axis type. Most of the wind turbines use two or three blades which have been configured with the horizontal axis. The wind turbine operates either down-wind or up-wind. Most turbine manufacturers have opted for reduction gears between the low speed turbine rotor and the high speed three-phase generators [1]. The characteristics of the wind turbine have been analyzed using the pitch controller which is shown as in Figure 2.1.

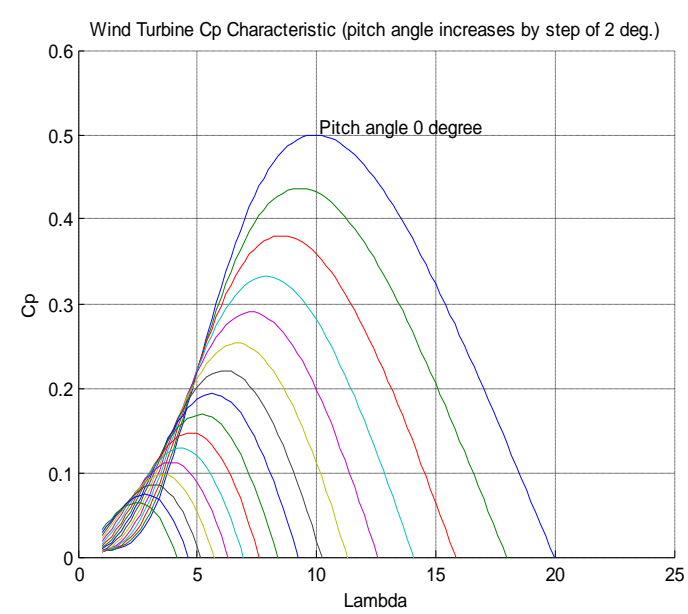

Fig 2.1 Characteristics of wind turbine 
Recently, the design of wind turbines using doubly-fed induction generator (DFIG) which consists of a rotor induction generator and an $\mathrm{AC} / \mathrm{DC} / \mathrm{AC}$ converter is very popular. The stator winding is connected directly to the $50 \mathrm{~Hz}$ grid while the rotor is fed at variable frequency through the AC/DC/AC converter. The DFIG generator allows extracting the maximum wind energy from the wind for the low wind speeds by optimizing the wind turbine speed, while it minimizes the mechanical stresses on the wind turbine. Another advantage of the DFIG is to elimination of usage of capacitors. Also it has the ability to generate power using converters or it absorbs the reactive power. Speed can be adjusted to the desired value by controlling torque. Variable speed turbines can be made to capture this maximum energy in the wind by operating them at a blade speed that gives the optimum tip speed ratio. This may be done by changing the speed of the turbine in proportion to the change in wind speed [7].

\subsection{Doubly-Fed Induction Generator System}

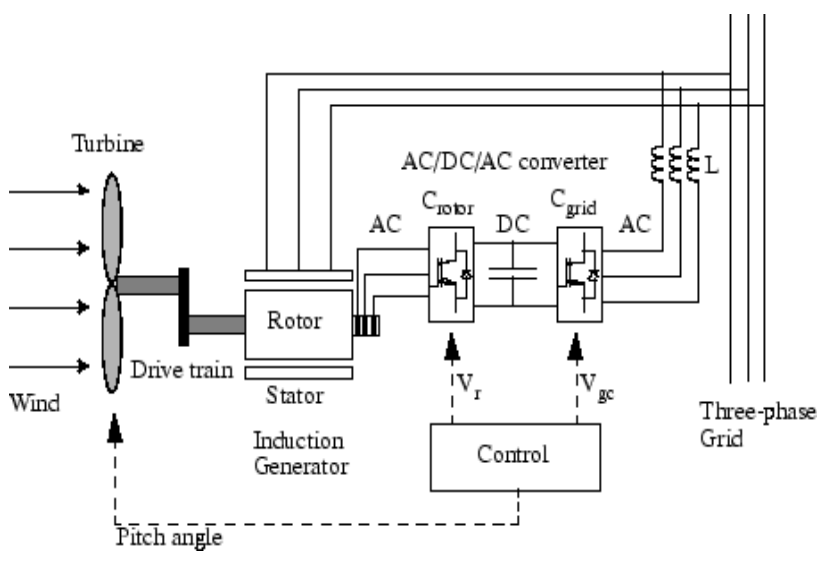

Fig 2.2 Doubly fed Induction generator system

The wind turbine and the doubly-fed induction generator (WTDFIG) are shown in the figure 2.2. The AC/DC/AC converter is divided into two components: the rotor-side converter $\left(\mathrm{C}_{\text {rotor }}\right)$ and the grid-side converter $\left(\mathrm{C}_{\text {grid }}\right)$. $\mathrm{C}_{\text {rotor }}$ and $\mathrm{C}_{\text {grid }}$ are Voltage-Sourced Converters that use forced-commutated power electronic devices (IGBTs) to synthesize an AC voltage from a DC voltage source [14]. A capacitor connected on the DC side acts as the DC voltage source. An inductor $\mathrm{L}$ which is used to connect the grid $\left(\mathrm{C}_{\text {grid }}\right.$. The three-phase rotor winding is connected to $\mathrm{C}_{\text {rotor }}$ by slip rings and brushes and the three-phase stator winding is directly connected to the grid [14]. The control system generates the pitch angle command and the voltage command signals $\mathrm{V}_{\mathrm{r}}$ and $\mathrm{V}_{\mathrm{gc}}$ for $\mathrm{C}_{\text {rotor }}$ and $\mathrm{C}_{\text {grid }}$ respectively in order to control the power of the wind turbine, the DC bus voltage and the reactive power or the voltage at the grid terminals.

\subsection{Pitch Angle Control System}

The pitch angle is kept constant at zero degree until the speed reaches point $\mathrm{D}$ speed of the tracking characteristic. The pitch angle is proportional to the speed deviation from point D. For electromagnetic transients in power systems the pitch angle control is of less interest. The rotational speed should be less than the speed at point $\mathrm{D}$. The pitch control system is illustrated in figure 2.3 .

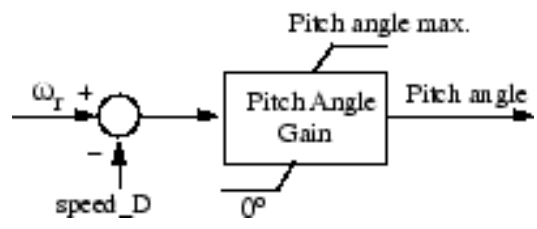

Fig 2.3 Pitch angle control system

\subsection{Fuzzy Logic Controller}

The control system is based on fuzzy logic. To manage the performance of the system the control makes use of the tolerance, uncertainty, imprecision and fuzziness in the decision-making process, just by incorporating the experts' knowledge into fuzzy rules.

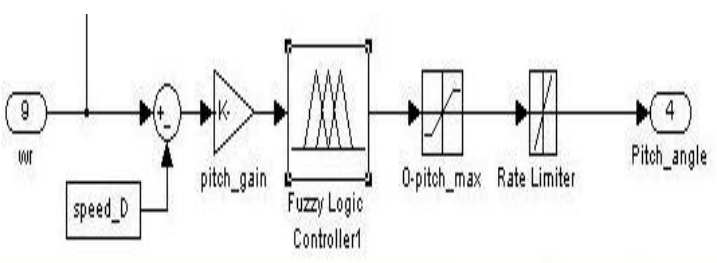

Fig 2.4 Fuzzy Logic Controller

The controller in Fuzzy Logic control (FLC) are more effective for complex, non-linear and imprecisely. It has defined that processes for which standard model based control techniques uses FLC. Fuzzy Logic, unlike Boolean or crisp logic, deals with problems that have vagueness, uncertainty and use membership functions with values varying between 0 and 1 . Fuzzy Logic tends to mimic human thinking that is often fuzzy in nature.

\subsection{Adaptive Neuro Fuzzy Algorithm}

The Neuro-Fuzzy control Network is a feed forward multilayer network, which integrates the basic elements, and functions of a traditional fuzzy logic controller into a connectionist structure thus had distributed learning abilities. In this connectionist structure, the input and output nodes represent the input states and output control or decision signals respectively.

The Neuro-Fuzzy is constructed from training examples by neural learning techniques using backpropagation learning algorithm and the connectionist structure can be trained to develop fuzzy logic rules and determine proper input-output membership function. 
The rule base of connectionist structure contains fuzzy IF-THEN rules of Sugeno's first order type in which the output of each rule is a linear combination of input variables plus a constant term.

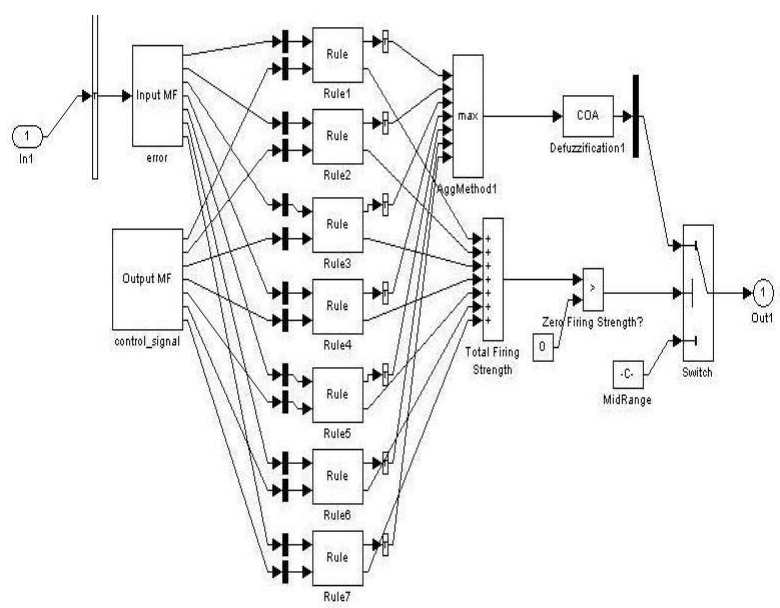

Fig 2.5 Adaptive Neuro fuzzy controller

For a first-order Sugeno type fuzzy model the common rule set with two fuzzy IF-THEN rules is the following.

Rule 1:

If $\mathrm{x}$ is $\mathrm{A}_{1}$ and $\mathrm{y}$ is $\mathrm{B}_{1}$ then $\mathrm{f}_{1}=\mathrm{p}_{1} \mathrm{x}+\mathrm{q}_{1} \mathrm{y}+\mathrm{r}_{1}$

Rule 2:

If $x$ is $A_{2}$ and $y$ is $B_{2}$ then $f_{2}=p_{2} x+q_{2} y+r_{2}$

The final output is the weighted average of each rule's output.

\subsection{Genetic Algorithm based Fuzzy Control System}

Genetic algorithms are search algorithms formulated on the Natural Selection Theory. They are based on the generation of a population formed by a random group of individuals that can be considered as possible solutions for a certain problem. In this paper, the main objective of the GA consists on finding the Fuzzy controller gains of the control loop associated with converter aiming to optimize, in particular, the DC voltage behavior of the AC-DC-AC link of the wind generator during the occurrence of short-circuits on the electrical grid. That is, from a refined tuning of the controller's gains, it is possible to reduce the DC voltage oscillations in consequence of the current imbalance between the DC and AC sides of converter provoked by the fault on the grid.

\section{MAXIMUM POWER POINT TRACKING SYSTEMS}

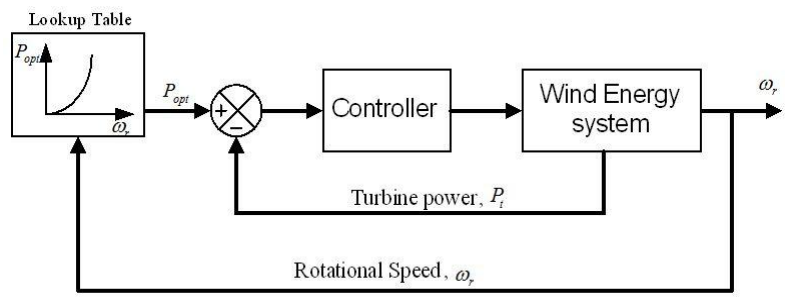

Fig 3.1 Maximum Power point Tracking System

The maximum power extraction algorithms researched so far can be classified into three main control methods, namely tip speed ratio (TSR) control, power signal feedback (PSF) control and hill-climb search (HCS) control [2]. The TSR control method regulates the rotational speed of the generator in order to maintain the TSR to an optimum value at which power extracted is maximum. This method requires both the wind speed and the turbine speed to be measured or estimated in addition to requiring the knowledge of optimum TSR of the turbine in order for the system to be able extract maximum possible power.

Figure 3.1 shows the block diagram of a WECS with TSR control. The MPPT control in such system is realized using the machine side control system. The MPPT controller generates at its output the optimum speed command for speed control loop of rotor flux oriented vector controlled machine side converter control system using only the instantaneous active power as its input.

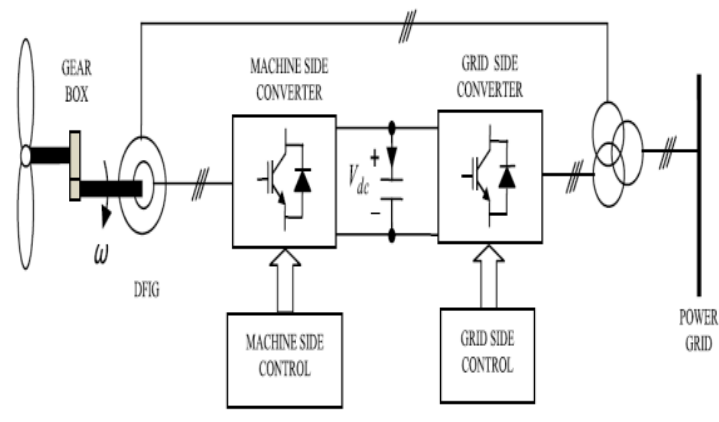

Fig 3.2 Wind Energy Conversion Systems

The optimum speed commands, which enable the WECS to track peak power points, are generated in accordance with the variation of the active power output due to the change in the command speed generated by the controller as shown in Figure 3.2. 


\section{SIMULATION RESULTS}

Turbine response to a change in wind speed

In the "Wind Speed" step block specifying the wind speed. Initially, wind speed is set at $8 \mathrm{~m} / \mathrm{s}$, then at $\mathrm{t}=5 \mathrm{~s}$, wind speed increases suddenly at $14 \mathrm{~m} / \mathrm{s}$. Start simulation and observe the signals on the "Wind Turbine" scope monitoring the wind turbine voltage, current, generated active and Reactive powers, DC bus voltage and turbine speed.

\begin{tabular}{|l|l|}
\hline Controller & ISE \\
\hline PID & 14.994 \\
\hline Fuzzy & 13.486 \\
\hline Neuro-Fuzzy & 12.897 \\
\hline GA tuned Fuzzy & 12.672 \\
\hline
\end{tabular}

TABLE 4.1

Table 4.1 gives the step response performance of various controllers. From the results it is very clear that the performance of intelligent controllers is better than PID controller.

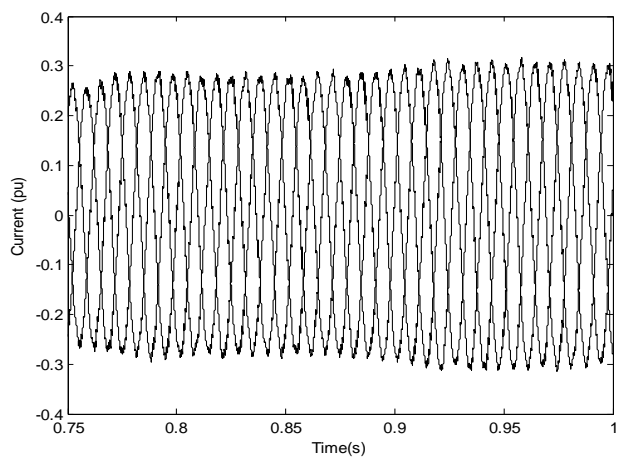

4.1 Measured Current in pu

\section{CONCLUSION}

The paper discusses the application of various intelligent control algorithms in pitch angle control of wind energy conversion system using DFIG. Fuzzy, neuro-fuzzy, GA tuned fuzzy controllers are designed for a sample 8 units of identical 1.5 MW wind generator system connected grid. The simulation results show that the performance of intelligent controllers is better than conventional PID controller. Among the intelligent controllers, GA-tuned fuzzy controller gives better performance in terms of ISE.

\section{REFERENCES}

[1] Liuchen Chang "Wind Energy Conversion Systems", IEEE Canadian Review - spring / Printemps, pp. 12$16,2010$.

[2] Abdel Aitouche and Elkhatib Kamal, "Intelligent Control of Wind Energy Conversion Systems", ISBN: 978-953-307-467-2, InTech, 2011.

[3] Q. Wang and L. Chang, "An intelligent maximum power extraction algorithm for inverter-based variable speed wind turbine systems," IEEE Trans. Power Electron., vol. 19, no. 5, pp. 1242-1249, Sept. 2004.

[4] M. Bayat, M. Sedighizadeh and A. Rezazadeh, "Wind Energy Conversion Systems Control Using Inverse Neural Model Algorithm", International Journal of Engineering and Applied Sciences (IJEAS) Vol.2, Issue 3(2010)40-46, march 2010.

[5] Danish Wind Power Association. www.windpower.org.

[6] J. Yaoqin, Y. Zhongqinq, and C. Binggang. "A New Maximum Power Point

Tracking Control Scheme for Wind Generation" IEEE International Conference

on Power System Technology 2002. vol. 1, October 2002. pp. 144-148.

[7] B.Chitti Babu , K.B.Mohanty "Doubly-Fed Induction Generator for Variable Speed Wind Energy Conversion Systems- Modeling \& Simulation "International Journal of Computer and Electrical Engineering, February, 2010.

[8] H. Li, K. L. Shi, and P. G. McLaren, "Neuralnetwork-based sensorless maximum wind energy capture with compensated power coefficient", IEEE Transactions on Industry Applications, Vol. 41, No. 6, pp. 1548-1556, Nov./Dec. 2005.

[9] J.S.R Jang, Chuen-Tsai Sun and Eiji Mizutani, "Neuro-Fuzzy and Soft Computing - A Computational Approach to Learning and Machine Intelligence", Prentice Hall of India, ISBN-81-2032243-6, 2006.

[10] K. Tan and S. Islam, "Optimal control strategies in energy conversion of PMSG wind turbine system without mechanical sensors," IEEE Transactions on Energy Conversion, Vol. 19, No. 2, pp. 392-399, Jun. 2004.

[11] M. G. Simoes, B. K. Bose, and R. J. Spiegel, "Fuzzy logic based intelligent control of a variable speed cage machine wind generation system", IEEE Transactions on Power Electronics, vol. 12, no. 1, pp. 87-95, Jan. 1997.

[12] Quincy Wang, “An Intelligent Maximum Power Extraction Algorithm for Inverter-Based Variable Speed Wind Turbine Systems", IEEE Transactions on Power Electronics, Vol. 19, No. 5, September 2004, pp: 1242-1249.

[13] S. Bhowmik, R. Spee, and J. H. R. Enslin, "Performance optimization for doubly fed wind power generation systems," IEEE Transactions on Industry Applications, Vol. 35, No. 4, pp. 949-958, Jul./Aug.

1999. 